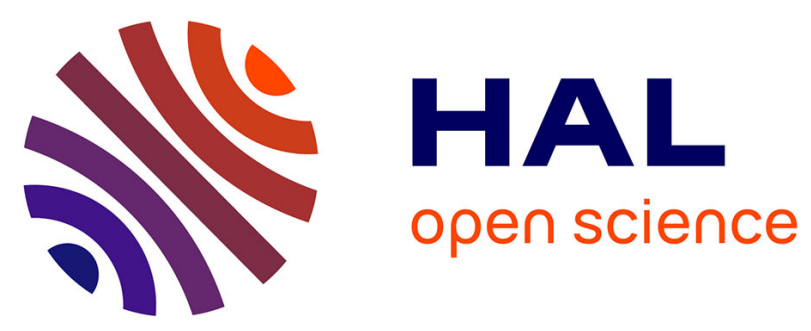

\title{
Single amino-acid mutation in the Drosophila melanogaster ribosomal protein uL11: an insight in its transcriptional activity
}

Héloïse Grunchec, Jérôme Deraze, Delphine Dardalhon-Cuménal, Valérie Ribeiro, Anne Coléno-Costes, Karine Dias, Sébastien Bloyer, Emmanuèle

Mouchel-Vielh, Frédérique Peronnet, Hélène Thomassin

\section{To cite this version:}

Héloïse Grunchec, Jérôme Deraze, Delphine Dardalhon-Cuménal, Valérie Ribeiro, Anne ColénoCostes, et al.. Single amino-acid mutation in the Drosophila melanogaster ribosomal protein uL11: an insight in its transcriptional activity. 2021. hal-03453229

\section{HAL Id: hal-03453229 \\ https://hal.sorbonne-universite.fr/hal-03453229}

Preprint submitted on 28 Nov 2021

HAL is a multi-disciplinary open access archive for the deposit and dissemination of scientific research documents, whether they are published or not. The documents may come from teaching and research institutions in France or abroad, or from public or private research centers.
L'archive ouverte pluridisciplinaire HAL, est destinée au dépôt et à la diffusion de documents scientifiques de niveau recherche, publiés ou non, émanant des établissements d'enseignement et de recherche français ou étrangers, des laboratoires publics ou privés. 


\section{Single amino-acid mutation in the Drosophila melanogaster ribosomal protein uL11: an insight in its transcriptional activity}

Héloïse Grunchec ${ }^{1}$, Jérôme Deraze ${ }^{1}$, Delphine Dardalhon-Cuménal ${ }^{1}$, Valérie Ribeiro ${ }^{1}$, Anne Coléno-Costes ${ }^{1}$, Karine Dias ${ }^{2}$, Sébastien Bloyer ${ }^{3}$, Emmanuèle Mouchel-Vielh ${ }^{1}$, Frédérique Peronnet $^{1 *}$ and Hélène Thomassin ${ }^{1 *}$

* Co-last and co-corresponding authors

1 Sorbonne Université, Centre National de la Recherche Scientifique (CNRS), Institut de Biologie Paris Seine (IBPS), Laboratoire de Biologie du développement (LBD), F75005 Paris, France

${ }^{2}$ Genomics core facility, Institut de Biologie de l'ENS (IBENS), Département de biologie, École normale supérieure, CNRS, INSERM, Université PSL, 75005 Paris, France

${ }^{3}$ Université Paris-Saclay, CEA, CNRS, Institute for Integrative Biology of the Cell (I2BC), F91190 Gif-sur-Yvette, France

\section{ABSTRACT}

The ribosomal protein $\mathrm{uL} 11$ is located at the basis of the ribosome P-stalk and plays a paramount role in translation efficiency. In addition, no mutant for $u L 11$ is available suggesting that this gene is haplo-insufficient as many other Ribosomal Protein Genes (RPGs). We have previously shown that overexpression of Drosophila melanogaster uL11 induces the transcription of many RPGs and Ribosomal Biogenesis genes (RiBis) suggesting that uL11 might globally regulate the level of translation through its transcriptional activity. Moreover, $\mathrm{uL} 11$ trimethylated on lysine 3 (uL11 K3me3) interacts with the chromodomain of the Enhancer of Polycomb and Trithorax Corto. uL11, Corto and RNA Polymerase II co-localize at many sites on polytene chromosomes. These data have led to the hypothesis that the $\mathrm{N}$-terminal end of uL11, and more particularly the trimethylation of lysine 3, supports the extra-ribosomal activity of UL11 in transcription. To address this question, we mutated the lysine 3 codon using a CRISPR/Cas9 strategy and obtained several lysine 3 mutants. We describe here the first mutants of $D$. melanogaster $u L 11$. Unexpectedly, the $u L 11^{K 3 A}$ allele, in which the lysine 3 codon is replaced by an alanine, displays a genuine Minute phenotype known to be characteristic of RPG deletions (longer development, low fertility, high lethality, thin and short bristles) whereas the $u L 11^{K 3 Y}$ allele, in which the lysine 3 codon is replaced by a tyrosine, is unaffected. In agreement, the translation rate slightly decreases in $u L 11^{K 3 A}$ but not in $u L 11^{K 3 Y}$. Deep-sequencing of RNA from wing imaginal discs shows enrichment in the GO categories "glutathione metabolism" for up-regulated genes in both mutants and "regulation of transcription" for down-regulated genes in $u L 11^{K 3 A}$. Furthermore, analysis of deregulated 
genes' cis-regulatory sequences suggests that uL11 might regulate transcription of target genes in concert with the couple of transcription factors Mad/Med that mediate response to the Bone Morphogenetic Protein (BMP) signaling pathway. 


\section{INTRODUCTION}

Loss of function alleles of Ribosomal Protein Genes (RPGs) have been studied for almost a hundred years in Drosophila, where they are known as Minute mutations (1). Minute mutants were first described for displaying thin and short bristles, i.e. Minute bristles, together with prolonged development (2). All Minute mutations are dominant and lethal when homozygous. The vast majority of them strongly impact viability and fertility, to the point that some could only be identified through transient aneuploidy experiments. Minute loci have been characterized over time and the Minute genes have now been identified to encode ribosomal proteins with very few exceptions $(3,4)$.

While a substantial part of ribosomal proteins' contribution to cell metabolism has been attributed to their ability to alter ribosome behaviour with consequences on protein synthesis, some free ribosomal proteins are also known for a long time to carry regulatory activities, consequently termed "extra-ribosomal functions" [for a review see (5)] This is notably the case for RPL12, aka uL11 following the new nomenclature recently proposed to avoid confusion between species (6). Indeed uL11 was shown in C. elegans and mammals to bind its own messenger RNA and inhibit its splicing $(7,8)$. Furthermore, in S. cerevisiae, uL11 was shown to be required for the transcription of a subset of $\mathrm{PHO}$ pathway genes that are inducible under low phosphate conditions (9).

Drosophila melanogaster uL11 is encoded by a unique gene (uL11/RPL12) CG3195/FBgn0034968) located on the right arm of chromosome 2 at cytogenetic position 60B7. Three annotated transcripts encode the same 165 amino acid protein. $u L 11$ expression is ubiquitous and described as "very high" to "extremely high" in all tissues, developmental stages, and cell lines (10). Two deletions encompassing the whole $u L 11 / R p L 12$ area have been described [i.e. $D f(2 R) b w^{V D e} L P x^{K R}$ and $\left.D f(2 R) E x e / 6081\right]$. However, it was recently proposed that the cytological borders of the first one did not cover the $u L 11 / R p L 12$ region (FBrf0230794) and the second one was lost (FBrf0206661). Thus, no evidence remains that flies can accommodate aneuploidy at this locus, which is indeed described as haplolethal $(4,11)$. Another RPG (eL39/RpL39), and several essential genes (elF5A, $y k i)$ are found in the vicinity of $u L 11 / R p L 12(12,13)$. For this reason, the genes responsible for this haplolethality remain uncertain. However, it is likely that $u L 11 / R p L 12$ contributes to this phenotype as no classical allele of $u L 11$ has been described and we observed that ubiquitous RNAi mediated inactivation is lethal during the first larval instar.

The $\mathrm{uL} 11$ protein forms, together with the ribosomal protein $\mathrm{uL} 10$, the base of the Pstalk, a lateral protuberance of the $60 \mathrm{~S}$ subunit which is a critical element of the ribosomal GTPase-associated center known to interact with translational elongation and termination factors (14). The uL11 protein consists of two globular domains connected with a hinge, a C- 
terminal domain anchored to a conserved region of the 28S rRNA and a mobile N-terminal domain. The $\mathrm{N}$-terminal domain interacts with several translation factors, notably eEF2 $(14,15)$. As a consequence, uL11 has been shown to play an important role at many steps of the translation cycle. In yeast, deficiency of uL11 prevents the release of the ribosome associated protein Tif6, which is the last maturation step before the $60 \mathrm{~S}$ subunit becomes functional (16). Yeast uL11 deficient ribosomes display a decrease in translational fidelity (16), and depletion of uL11 in cultured human Cystic Fibrosis bronchial epithelial cells reduces the rate of translation initiation and elongation (17).

We have recently established that Drosophila melanogaster uL11 is bound by a chromodomain-like structure of the epigenetic co-factor Corto. Chromodomains are known to specifically recognize trimethylated lysines on histones, and the interaction between uL11 and Corto was indeed shown to require uL11 lysine 3 to be trimethylated (uL11K3me3). Trimethylation of uL11 lysine 3 is very conserved and has been confirmed in S. cerevisiae, $S$. pombe and $A$. thaliana (18-20). In D. melanogaster, uL11 and Corto bind chromatin, colocalize on many sites on polytene chromosomes and are recruited on the $h s p 70$ gene upon transcriptional activation (21). Overexpression of the Corto chromodomain as well as uL11 induces the transcription of many RPGs and Ribosomal Biogenesis genes (RiBis) suggesting that uL11 might globally regulate the level of translation through its transcriptional activity. Thus, our previous study led us to hypothesize that uL $11 \mathrm{~K} 3 \mathrm{me} 3$ is involved in transcriptional regulation.

To test this hypothesis, we designed a CRISPR/Cas9 strategy for mutating the uL11 lysine 3 codon. We describe here the $u L 11^{K 3 A}$ and $u L 11^{K 3 Y}$ mutants in which the lysine 3 codon of $u L 11$ is replaced by an alanine and a tyrosine codon, respectively. $u L 11^{K 3 A}$ displays Minute phenotypes i.e. longer development, low fertility, high lethality and thin bristles, but surprisingly $u L 11^{K 3 Y}$ looks wild-type. RNA-seq analysis of wing imaginal discs from both mutants show enrichment of up-regulated genes in the GO category "glutathione metabolism" and downregulated genes in the GO category "regulation of transcription". Analysis of deregulated genes' cis-regulatory sequences suggests that uL11 might act in concert with the couple of transcription factors Mad/Med that are primary effectors in the Bone Morphogenetic Protein (BMP) signaling pathway.

\section{MATERIALS AND METHODS}

\section{Drosophila genetics}

Drosophila melanogaster stocks and crosses were kept on standard yeast corn-meal medium ( $7.5 \%$ yeast, $9 \%$ cornmeal, $1 \%$ agar, $0.27 \%$ moldex) at $25{ }^{\circ} \mathrm{C}$. For all experiments, crosses were set up with similar densities to prevent confounding effects of overcrowding. 
$w^{1118}$ was used as the control strain. The $c{ }^{4}{ }^{420}$ and $c^{2}{ }^{21}{ }^{L 1}$ alleles were described in (21).

\section{Strategy of CRISPR/Cas9 mutagenesis}

The $p U 6$-chiRNA:sgRNA plasmid was obtained by incorporating the $s g R N A$ sequence (obtained by annealing phos-gRNA-F and phos-gRNA-R, Supplementary Table 1) into pU6Bbsl-chiRNA (Addgene plasmid \# 45946) (22) following the protocol provided on http://flycrispr.molbio.wisc.edu/protocols/gRNA. Sequence was confirmed using the T3 universal primer.

A 123 nucleotides long single-stranded DNA (ssODN) carrying the lysine (AAA) to alanine (GCC) substitution flanked by two 60 nucleotide-long homology arms was used as a template for Homologous Directed Repair (HDR) (synthetized and purified by standard desalting by Integrated DNA Technologies, Inc) (Supplementary Table 1). The uL11 region of the recipient line vasa-Cas9 (BL-51324) was sequenced in order to respect possible polymorphisms. To prevent base pairing with the $s g R N A$, the $s s O D N$ was designed to be homologous to the PAM carrying strand.

\section{Fly transgenesis}

Two hundred vasa-Cas 9 embryos were injected with a mixture containing $100 \mathrm{ng} / \mathrm{\mu L}$ pU6-chiRNA:sgRNA and $100 \mathrm{ng} / \mu \mathrm{L}$ ssODN (BestGene Inc.). Transformant G0 flies (48 females and 44 males) were individually crossed to $w^{1118}$; In(2LR)Gla, wgGla1/SM5 flies (Gla/SM5). Among them, only 18 males and 11 females were fertile. Curly wing G1 siblings were individually crossed to Gla/SM5 flies. Once the $\mathrm{G} 2$ progeny born, $\mathrm{G} 1$ founding flies were harvested, genomic DNA extracted, and genotyping performed as described below. 294 G1 individuals were genotyped to detect the presence of $u L 11$ mutant alleles. Curly wing G2 offspring of $\mathrm{G} 1$ flies carrying a mutant allele of $u L 11$ were crossed with each other to establish mutant balanced strains. In order to eliminate potential unspecific mutations, balanced mutant females were crossed with $w^{1118}$ males. Ten heterozygous mutant females from the offspring were then individually backcrossed with $w^{1118}$ males and genotyped by HRMA after laying eggs. uL11 mutant females were kept and the whole procedure was repeated seven times.

\section{Genomic DNA extraction}

Genomic DNA was extracted by crushing single flies in $100 \mu \mathrm{L}$ SB buffer (10 mM Tris $\mathrm{pH}$ 8.0, $1 \mathrm{mM}$ EDTA, $25 \mathrm{mM} \mathrm{NaCl}, 200 \mu \mathrm{g} / \mu \mathrm{L}$ Proteinase K), followed by 30 min incubation at $37^{\circ} \mathrm{C}$. DNA was further purified by standard phenol-chloroform extraction followed by ethanol precipitation.

\section{Locked Nucleic Acid allele-specific qPCR}


Forward allele-specific primers with 3' end matching either wild-type (LNAWT) or mutated $3^{\text {rd }}$ codon ( $L N A K 3 A$ ) of $u L 11$ (AAA or GCC, respectively) and a Locked Nucleic Acid (LNA) nucleotide (23) at the second position of the mismatch codon were used in combination with a reverse primer (CRISPR1_R) to amplify a 219 nucleotide fragment (Supplementary Table 1). $25 \mu \mathrm{L}$ reactions were set to contain 5 to $15 \mathrm{ng}$ of genomic DNA, $0.5 \mu \mathrm{M}$ forward and reverse primers, $0.4 \mathrm{nM}$ dNTP, $0.75 \mu \mathrm{L}$ SYBR green (Diagenode), and 2.5 units of DreamTaq polymerase (Thermo Fisher Scientific) in TMAC buffer (67 mM Tris $\mathrm{pH} 8.8,6.7 \mathrm{mM} \mathrm{MgCl}$, $16.6 \mathrm{mM}$ ammonium sulfate, $0.5 \mathrm{mM}$ tetramethylammonium chloride, $0.17 \mathrm{mg} / \mathrm{mL}$ BSA) (24). qPCR plates were prepared and kept at $4^{\circ} \mathrm{C}$ until starting PCR cycles. $0.5 \mathrm{ng}$ of plasmid containing the $u L 11$ coding region in which the AAA lysine 3 codon was replaced by GCC was used as positive control. qPCRs were carried out in a CFX96 system (BioRad) $\left[95^{\circ} \mathrm{C} 3 \mathrm{~min}\right.$; 40 cycles $\left(95^{\circ} \mathrm{C} 20 \mathrm{~s}, 64^{\circ} \mathrm{C} 20 \mathrm{~s}, 72^{\circ} \mathrm{C} 30 \mathrm{~s}\right)$ ]. To confirm the presence of the mutated allele, a $1.5 \mathrm{~kb}$ region centred on the lysine 3 codon was amplified from positive genomic DNA and sequenced.

\section{High Resolution Melting Analysis (HRMA)}

Genomic DNA was analysed by High Resolution Melting Analysis (HRMA) as described by (25). Briefly, oligonucleotides $u L 11-H R M A-F$ and $U L 11-H R M A-R$ (Supplementary Table 1) were used to amplify a 173 bp region centred on the $u L 11$ lysine 3 codon. PCR were performed with Sso Fast Eva Green SupermixTM (BioRad) in $20 \mu \mathrm{L}$ reactions containing 2 to $15 \mathrm{ng}$ genomic DNA and $0.5 \mu \mathrm{M}$ each oligonucleotide. Cycles were carried out in a CFX96 system (BioRad) [98 ${ }^{\circ} \mathrm{C} 3 \mathrm{~min} ; 40$ cycles $\left.\left(98^{\circ} \mathrm{C} 2 \mathrm{~s}, 57.3^{\circ} \mathrm{C} 15 \mathrm{~s}\right)\right]$. Thermal melting profiles were obtained in the same device by increasing temperature from 75 to $95{ }^{\circ} \mathrm{C}$ using a temperature increment of $0.2^{\circ} \mathrm{C}$. They were normalized as described by (26).

\section{uL11K3me3 antibodies}

Polyclonal uL11K3me3 antibodies were generated in rabbit using a peptide corresponding to the first 16 amino acids of $\mathrm{uL} 11$ with methylated lysine 3 [PPK(me3)FDPTEVKLVYLRC] (Eurogentec). The serum was first loaded on a uL11K3me3 peptide affinity column which allowed to retain uL11K3me3 and uL11 antibodies. After elution, unmethylated $\mathrm{uL} 11$ and $\mathrm{uL} 11 \mathrm{~K} 3 \mathrm{me} 3$ antibodies were separated by passage through an unmethylated UL11 peptide affinity column. Specificity of the antibodies was checked by dot blot (Supplementary Figure 1).

Proteins were extracted from third instar larvae in RIPA buffer $(150 \mathrm{mM}$ sodium chloride, $1 \%$ NP40, $0.5 \%$ sodium deoxycholate, $0.1 \%$ SDS, $50 \mathrm{mM}$ TrisHCl pH 8,0) supplemented with phosphatase and protease inhibitors (Roche). $30 \mu \mathrm{g}$ of proteins were separated by SDS-PAGE electrophoresis on $15 \%$ acrylamide gels. Western blots were 
performed according to standard protocols using either goat anti-uL11 (SantaCruz sc82359, 1/1000), rabbit anti-uL11K3me3 (1/6000), or mouse anti-a-tubulin (DSHB E7c, 1/2500) as primary antibodies. Anti-goat (Jackson ImmunoResearch; 705035147; 1/10000), anti-rabbit $(1 / 20000)$ or anti-mouse (Sigma NA931; 1/20000) were used as secondary antibodies.

\section{Analysis of mutant life history traits}

uL11 wild-type or mutant chromosomes were balanced with CyO,Dfd-EYFP (from strain BL-8578) or SM5. About 100 females and 60 males were placed in laying cages on agarose plates ( $2 \%$ agarose, $5 \%$ vinegar, neutral red) supplemented with yeast. To measure embryonic lethality, 100 embryos were collected from each laying cage, transferred on new agarose plates and emerging first instar larvae were counted. To measure larval and pupal lethality, 100 embryos were collected and transferred into yeast cornmeal medium tubes at $25^{\circ} \mathrm{C}$. Pupae and adults were then counted. Three independent experiments were performed and results were pooled. To measure developmental time, first instar larvae were collected and transferred into yeast cornmeal medium tubes at $25^{\circ} \mathrm{C}$ (50 to 100 larvae per tube). Vials were checked from 9 days after egg laying until no more adults emerged. Chi ${ }^{2}$ tests were performed to compare genotypes.

\section{Measure of bristle length}

Adult bodies free of wings, legs and heads were aligned on agar cups. Images were captured using a Leica Model MZ FLIII microscope equipped with a Leica Model DC480 camera. Scutellar bristles were measured using the ImageJ segmented line tool. Normality was checked by Shapiro-Wilk tests and homogeneity of variances by F tests. Student's t-tests were then set taking into account homo- or heteroscedasticity of variances.

\section{Measure of wings}

Adult flies were kept in $70 \%$ ethanol for $48 \mathrm{~h}$ and transferred into PBS glycerol $(1: 1 \mathrm{v} / \mathrm{v})$. Wings were dissected and mounted on glass slides, dorsal side up, in Hoyer's medium. Slides were scanned with a Hamamatsu Nanozoomer Digital Slide scanner, running the Nanozoomer software with a $20 \mathrm{x}$ objective and an 8 bit camera. Wing pictures were separately exported into tif format using NDP.view and the $5 \mathrm{x}$ lens. Measurements of wing length were performed as described in (27).

\section{Plasmids}

$u L 11$ was amplified from $w^{1118}$ embryonic cDNAs and subcloned into $p E N T R / D-T O P O$ (Invitrogen) (21). pENTR-uL11 $1^{K 3 A}$ and $p E N T R-u L 11^{K 3 Y}$ were obtained by site-directed mutagenesis using the oligonucleotides described in (21) and in Supplementary Table 1 , 
respectively. The cDNAs were then transferred either into the $p A W M$ or the $p A W H$ Gateway ${ }^{\circledR}$ Drosophila vector allowing expression of fusion proteins with a C-terminal Myc or HA tag, respectively.

\section{Cell transfection}

S2 cells were cultured at $25^{\circ} \mathrm{C}$ in Schneider's Drosophila medium supplemented with $10 \%$ heat-inactivated foetal bovine serum and 100 units $/ \mathrm{mL}$ of penicillin and streptomycin (Life technologies). To obtain cells permanently expressing $u L 11^{K 3 A}$, a mix containing a $5: 1$ molar ratio of the $p A-u L 11^{K 3 A}-H A$ expression vector and the selection plasmid $p C o B l a s t$ was prepared. $10^{6}$ cells were then transfected with $2 \mu \mathrm{g}$ of DNA using Effecten $®$ transfection reagent (Qiagen) according to the manufacturer's instructions at a 1:10 DNA/Effecten ${ }^{\circ}$ ratio. Selection was performed by addition of $10 \mu \mathrm{g} / \mathrm{mL}$ of blasticidin after $48 \mathrm{~h}$. After initial selection, stable cell lines were cultured in presence of $2 \mu \mathrm{g} / \mathrm{mL}$ of blasticidin. For transient expression, $10^{6}$ cells were transfected with $2 \mu \mathrm{g}$ of either $p A-u L 11^{K 3 A}-M y c$ or $p A-u L 11^{K 3 Y}-M y c$ vector using Effecten $\circledast$ at a 1:10 DNA/Effecten $®$ ratio.

\section{Polysome fractionation}

Cells were harvested at $50 \%$ confluence and washed in Schneider medium at room temperature to remove the foetal bovine serum. They were then resuspended in ice-cold lysis buffer (20 mM Hepes pH 7.5, $250 \mathrm{mM} \mathrm{KCl,} 10 \mathrm{mM} \mathrm{MgCl2,} 5 \mathrm{mM}$ DTT, 1 mM EDTA, $0.5 \%$ NP-40) supplemented with EDTA-free protease inhibitor cocktail (Roche Diagnostics) and $40 \mathrm{U} / \mathrm{mL}$ Ribolock RNAse Inhibitor (ThermoFisher). For EDTA treatment, the lysis buffer was replaced with (20 mM Hepes pH 7.5, $250 \mathrm{mM} \mathrm{KCl,} 5$ mM DTT, 25 mM EDTA, 0.5 \% NP-40). After centrifugation at $500 \mathrm{~g}$ for $5 \mathrm{~min}$ to pellet nuclei, supernatants were layered onto 10 to $50 \%$ sucrose gradients in polyribosome buffer $(20 \mathrm{mM}$ Hepes pH 7.5, $250 \mathrm{mM} \mathrm{KCl}, 20 \mathrm{mM}$ $\mathrm{MgCl}$, $2 \mathrm{mM}$ DTT), supplemented with EDTA-free protease inhibitor cocktail (Roche Diagnostics) and $40 \mathrm{U} / \mathrm{mL}$ Ribolock RNAse Inhibitor (ThermoFisher). Gradients were centrifugated at $39,000 \mathrm{rpm}$ for $165 \mathrm{~min}$ at $4{ }^{\circ} \mathrm{C}$ in a Beckman SW41-Ti rotor. Optical density at $254 \mathrm{~nm}$ was monitored using a density gradient fractionator (Teledyne Isco, Lincoln, NE).

\section{Puromycin assays}

Puromycin assays were adapted from (28) with the following modifications: 20 larvae were turned inside out and incubated for $1 \mathrm{~h}$ at $25^{\circ} \mathrm{C}$ under gentle rotation in Schneider's medium supplemented or not with $10 \mathrm{mg} / \mathrm{mL}$ cycloheximide (Sigma). Puromycin (antpr1, InvivoGen) was then added at a final concentration of $0.28 \mathrm{mg} / \mathrm{mL}$ and incubation was continued for $2 \mathrm{~h}$. 
Total proteins were extracted from third instar larvae in buffer containing [ $30 \mathrm{mM}$ Hepes pH 7.4, 0.1\% NP40, $150 \mathrm{mM} \mathrm{NaCl}, 2 \mathrm{mM} \mathrm{Mg}(\mathrm{OAc})_{2}$ ] supplemented with phosphatase and protease inhibitors (Roche) (adapted from (29). $60 \mu \mathrm{g}$ of protein extracts were deposited on a $12 \%$ acrylamide gel.

Western blot analyses were performed according to standard protocols with mouse anti-puromycin (Kerafast, 3RH11; 1/500) or mouse anti-H3 (Diagenode; C15200011;1/1000) as primary antibodies and anti-mouse (Sigma; NA931; 1/20000) as secondary antibodies. Background, puromycin and $\mathrm{H} 3$ signals were measured using ImageJ. The puromycin signal was normalized towards the $\mathrm{H} 3$ signal. Results were submitted to Student's t-tests.

\section{Co-Immunoprecipitation}

Cells transiently transfected with either $p A-u L 11^{K 3 A}-M y c$ or $p A-u L 11^{K 3 Y}-M y c$ and $p A-$ FLAG-CortoCD (21) were harvested after $48 \mathrm{~h}$ and washed in Schneider medium at room temperature. Co-immunoprecipitations were performed as described in (30) without fixation. $30 \mu$ of Protein G coated Bio-Adembeads (Ademtech) were incubated with either $1 \mu \mathrm{g}$ of mouse monoclonal anti-FLAG antibody (F3165, Sigma), or goat anti-HA antibody as mock (sc-805, Santa Cruz Biotechnology).

Western blot analyses were performed according to standard protocols with mouse anti-Myc (Abcam ab9132 1/10000) or anti-FLAG (Sigma F3165 1/5000) as primary antibodies and anti-mouse (Sigma NA931; 1/20000) as secondary antibodies.

\section{RNA-seq and bioinformatic analyses}

Wing imaginal discs of third instar female larvae (one disc per larva) were dissected by batches of 50 in ice-cold PBS and frozen in liquid nitrogen. 150 discs (three batches) were pooled and homogenized in lysis buffer by pipetting. Total RNAs were extracted using RNeasy kit (Qiagen).

Preparation of library and sequencing of $\mathrm{CDNA}$ from corto $^{420} / \mathrm{corto}^{L 1}$ wing imaginal discs were performed as described in (21). For $U L 11$ wing imaginal discs, library preparation was performed using the TruSeq ${ }^{\circledR}$ Stranded mRNA Library Prep kit (Illumina). Library preparation and Illumina sequencing were performed at the Ecole normale superieure genomics core facility (Paris, France) on a NextSeq 500 (Illumina). Three replicates were sequenced for each genotype. 75 bp single reads were trimmed using FastQC (Galaxy version 0.72). Reads were then aligned against the $D$. melanogaster genome (dm6 genome assembly, release 6.30) using STAR (Galaxy Version 2.6.0b-2). Reads were counted using featurecount (Galaxy Version 1.6.0.6). Differential analysis was performed using DeSeq2 version 1.32.0. Gene ontology was analysed with DAVID (https://david.abcc.ncifcrf.gov/home.jsp). Motif discovery was performed using MEME (31) and motif comparison using TomTom (32) [MEME Suite, 
version 5.3.3, (33)]. The RNA-Seq gene expression data and raw fastq files are available at the GEO repository (https://www.ncbi.nlm.nih.gov/geo/info/seq.html) under accession number GSE181926.

RT-qPCR were performed on wing imaginal disc cDNAs as described in (27). Expression levels were quantified with the Pfaffl method (34) and normalized to the geometric mean of two reference genes, GAPDH and Spt6, the expression of which did not vary in the mutants. Sequences of primer couples are listed in Supplementary Table 1.

\section{RESULTS}

\section{CRISPR/Cas9 editing of the uL11 lysine 3 codon}

uL11 is located within a cluster of highly transcribed genes, many of which are also essential (eIF5A, RpL39/eL39, yki...) (12,13). Unsurprisingly, this cluster is part of the $1.6 \%$ haplolethal regions of the euchromatic Drosophila genome (4). The immediate neighbourhood of $u L 11$ contains only two small intergenic sequences (465 and $620 \mathrm{bp}$, respectively) that might contain regulatory elements (Figure $1 \mathrm{~A}$ ). Thus, the insertion of a selection cassette at any position inside this locus would likely disturb gene expression and impede viability. We therefore opted to edit the $u L 11$ lysine 3 to alanine (K3A) by a single step CRISPR/Cas9 mediated HDR using a single-stranded DNA donor template ( $s S O D N)$.

To recover the successful events, we set up a phenotype-independent screening protocol based on an allele specific amplification strategy. Discriminating power was increased by the substitution of the penultimate nucleotide of the screening primers with a locked nucleic acid (LNA) (Supplementary Figure 2A). The presence of a single LNA sufficiently improved specificity to allow us analyzing pools of flies for the presence of a single allele copy (Supplementary Figure 2B). 294 G1 individuals were tested for the presence of a mutated allele carrying the K3A substitution. Mixtures of genomic DNA from 4 to 5 individuals were prepared and the $u L 11$ locus was amplified with either the lysine codon (LNA-WT) or the alanine codon ( $L N A-K 3 A)$ matching primer. While most genomic DNA mixtures displayed amplification kinetics close to the level of the negative control, six of them exhibited faster amplification ( $\Delta \mathrm{Ct}$ between 2 and 7 ). We thus repeated the experiment on individual genomic DNAs from 6 pools. Ten genomic DNA originating from three independent $\mathrm{G} 0$ founding flies, two males and one female, exhibited quicker amplification with the LNA-K3A forward primer than with the control primer $(\Delta \mathrm{Ct}>5)$ (Supplementary Figure $2 \mathrm{C}$ ). Sequencing the $u L 11$ locus confirmed that they contained the recombinant allele $u L 11^{K 3 A}$ at the heterozygous state.

To detect other mutations potentially resulting from non-homologous end joining (NHEJ) events, we also performed High Resolution Melting Analysis (HRMA) of a qPCR amplicon centred on the $u L 11$ lysine 3 codon. Denaturation kinetics of these PCR products 
were analyzed individually for the $294 \mathrm{G} 1$ flies. Among them, 36 denaturation profiles differed from the wild-type control. Sequencing of the amplicons confirmed the presence of a mutation at the $u L 11$ locus in each of these 36 samples. Consistently, the $10 u L 11^{K 3 A}$ mutants identified with the allele-specific amplification strategy were also recovered by HRMA. Seven additional alleles were thus identified, that all carry a mutation impairing the lysine 3 codon: a single (K3Y) or double (P2LK3E, P2QK3R) amino acid substitutions, a single $(\Delta K 3)$ or double $(\Delta \mathrm{K} 3 \mathrm{~F} 4)$ amino acid deletion, and an insertion or a deletion of 4 nucleotides ( $\mathrm{F}-4$ and $\mathrm{F}+2$, respectively) (Supplementary Figure 3). Our first observations revealed that the mutants could be dispatched into two groups depending on the severity of their phenotypes. The first group contains the $K 3 A, \Delta K 3, \Delta K 3 F 4, F+2$ and $F-4$ alleles, and the second group the $K 3 Y, P 2 Q K 3 R$ and $P 2 L K 3 E$ alleles. We choose to focus on two representative alleles, $K 3 A$ and $K 3 Y$ (Figure $1 \mathrm{~B}$ and Supplementary Figures $2 \mathrm{D}$ and 3 ). They were introduced into the same controlled genetic background $\left(w^{1118}\right)$ and expression of the $\mathrm{uL} 11$ proteins was confirmed by western blot (Figure 2). As expected, uL11 K3me3 was not detected in the two homozygous mutants.

\section{Lethality and developmental delay of uL11 mutants}

We first examined the lethality of $u L 11$ mutants. The lethality rate depended on the mutant allele. Homozygous $u L 11^{K 3 Y}$ flies were fully viable, whereas very few $u L 11^{K 3 A}$ homozygotes emerged and almost all of them were males.

Next, we examined the lethality of the two mutants during development. During embryogenesis, they did not display more lethality than the $w^{1118}$ control with the exception of $u L 11^{K 3 A} / u L 11^{+}$whose lethality is slightly higher (Chi ${ }^{2}$ test, $\left.p<0.05\right)$ (Figure $3 A$ ). By contrast, during larval life, lethality was very high for $u L 11^{K 3 A} / u L 11^{+}$, and $u L 11^{K 3 A} / u L 11^{K 3 A}\left(\right.$ Chi ${ }^{2}$ test, $p<0.001$ ), but did not increase neither for $u L 11^{K 3 Y} / U L 11^{+}$nor for $u L 11^{K 3 Y} / u L 11^{K 3 Y}$ larvae. We did not observe any lethality during the pupal life for all genotypes. Similarly, developmental time from egg deposition to adult emergence was considerably extended for $u L 11^{K 3 A} / u L 11^{+}$ (up to $48 \mathrm{~h}$ ) and $u L 11^{K 3 A} / u L 11^{K 3 A}$ (up to $96 \mathrm{~h}$ ) but unaffected in $u L 11^{K 3 Y} / u L 11^{+}$and $u L 11^{K 3 Y} / U L 11^{K 3 Y}$ flies (Figure 3B).

To summarize, the K3Y mutation had no effect on these life history traits whereas lethality and developmental time were increased both in heterozygous and homozygous $K 3 \mathrm{~A}$ mutants, which characterized this allele as dominant.

\section{Bristle and wing size of the $u L 11$ mutants}

We noticed that the $u L 11^{K 3 A} / U L 11^{K 3 A}$ homozygous mutants had thinner and shorter macrochaetes as compared to wild-type flies (Figure 4A and B). To determine whether the size of the macrochaetes was affected, we measured the anterior and posterior scutellar bristles in males (Figure 4C and D). Scutellar bristles were significantly shorter in 
heterozygous and homozygous $u L 11^{K 3 A}$ but unaffected in homozygous $u L 11^{K 3 Y}$ males as compared to wild-type flies (Figure $4 \mathrm{C}$ and D). Similarly, we observed shorter bristles in heterozygous $u L 11^{K 3 A}$ females while $u L 11^{K 3 Y}$ homozygous females were only slightly affected (Supplementary Figure 4A and B). Wing length was also measured. Results show that wings were significantly shorter in heterozygous and homozygous $u L 11^{K 3 A}$ while unaffected in $u L 11^{K 3 Y}$ homozygous males (Figure 4E). Heterozygous $u L 11^{K 3 A}$ females exhibited shorter wings whereas wings of homozygous $u L 11^{K 3 Y}$ females were unaffected (Supplementary Figure 4C).

These results confirmed that $K 3 A$ was a dominant allele and showed that the severity of the phenotypes depended on the mutation. The $K 3 A$ mutation was highly detrimental while the K3Y mutation had almost no impact on the size of macrochaetes and wings. Minute mutants are known to be poorly fertile and viable, to exhibit developmental delay and have shorter and thinner bristles, all phenotypes that we observed in $u L 11^{K 3 A}$ mutant flies. Moreover, Minute alleles are dominant which is also the case of the $u L 11^{K 3 A}$ allele. All these data characterized the $u L 11^{K 3 A}$ mutant as a Minute mutant.

\section{Impact of the $u L 11$ mutations on translation}

The strategic location of uL11 protein at the base of the P-stalk in the GTPaseassociated center of the ribosome, suggests that its mutation might have a detrimental impact on translation. To test this hypothesis, we assessed the level of global translation in the $u L 11$ mutants. In order to label neo-synthesized proteins, third instar wild-type or mutant larvae were incubated with puromycin. Puromycin intake was normalized to histone H3 levels. A significant decrease in global translation level was observed in $u L 11^{K 3 A}$ heterozygous and homozygous larvae as compared to wild-type larvae, whereas it was unmodified in $u L 11^{K 3 Y}$ homozygous larvae (Figures $5 \mathrm{~A}$ and $\mathrm{B}$ ). These results were consistent with our previous phenotypic observations showing that $K 3 A$ mutation was the most detrimental.

We then asked whether the $\mathrm{uL} 11 \mathrm{~K} 3 \mathrm{~A}$ variant protein would retain the ability to associate with translating ribosomes. We generated stable cell lines expressing either uL11K3A-HA or uL11-HA under the control of the Actin promoter. Cytoplasmic extracts were purified from both genotypes and lysates were loaded onto sucrose gradients for fractionation. As a control, an extract of each genotype was supplemented with $25 \mathrm{mM}$ EDTA, a concentration that disrupts the interaction between ribosomal subunits and mRNA. The resulting fractions were analyzed by western blot to reveal the presence of UL11K3A-HA or uL11-HA (Figures 5C and 5D). These experiments revealed an enrichment of uL11-HA as well as $\mathrm{UL} 11 \mathrm{~K} 3 \mathrm{~A}-\mathrm{HA}$ at the $60 \mathrm{~S}$ and $80 \mathrm{~S}$ ribosomal fractions and at polysomal fractions but not at the $40 \mathrm{~S}$ fractions. In addition, the distribution of UL11K3A-HA was not biased towards inactive ribosomal fractions when compared to uL11-HA. Furthermore, EDTA treatment 
triggered the relocation of $\mathrm{uL} 11-\mathrm{HA}$ and $\mathrm{uL} 11 \mathrm{~K} 3 \mathrm{~A}-\mathrm{HA}$ towards lighter fractions, confirming that the sedimentation profiles truly resulted from their association with polysomes (Figures $5 \mathrm{C}$ and 5D). All these data showed that UL11K3A-HA was efficiently incorporated into translating ribosomes. Nevertheless, the decrease in puromycine incorporation observed in $u L 11^{K 3 A}$ mutants suggests that the yield of translation might be altered.

\section{Interaction between the Corto chromodomain and uL11 mutant proteins}

uL11 shares many transcriptional targets with Corto and interacts with its chromodomain through trimethylated lysine 3 (21). We thus hypothesized that the transcriptional activity of $u L 11$ was impaired in the $u L 11^{K 3 A}$ and $u L 11^{K 3 Y}$ mutants. To address this, we first assayed the physical interactions between the chromodomain and the two uL11 mutant proteins by co-immunoprecipitation. Drosophila S2 cells were co-transfected with $p A$ FLAG-CortoCD and either $p A-u L 11^{K 3 A}-M y c$ or $p A-u L 11^{K 3 Y}-M y c$. The FLAG-tagged chromodomain was immunoprecipitated using anti-FLAG antibodies. Contrarily to uL11-Myc that precipitated with FLAG-CortoCD, neither UL11K3A-Myc nor UL11K3Y-Myc coimmunoprecipitated with it (Figure 6). These results corroborated our previous results (21) and suggested that the transcriptional activity of uL11 might be at least partly impaired in the two mutants.

\section{Transcriptomic analysis of $u L 11$ mutants}

To address the role of $u L 11$ in transcriptional regulation, we deep-sequenced transcripts from third instar larval wing imaginal discs of homozygous mutants for $u L 11^{K 3 A}$, $u L 11^{K 3 Y}$ or trans-heterozygous mutants for corto (corto ${ }^{L 1} /$ corto $\left.^{420}\right)$. The $w^{1118}$ line was used as reference (Table 1). Differential analyses were performed to obtain adjusted p-values associated to expression fold-changes for the three genotypes as compared to the reference. Taken a $\log _{2}$ (fold-change) $<-0.5$ or $>0.50$ and an adjusted $p$-value $<0.05$, we found 458 down-regulated and 481 up-regulated genes in corto mutants (Supplementary Table 2). Using the same cutoffs, we found 152 down-regulated and 262 up-regulated genes in $u L 11^{K 3 A}$, and 39 down-regulated and 45 up-regulated genes in $u L 11^{K 3 Y}$ (Supplementary Table 2). Only 52 deregulated genes were shared by $U L 11^{K 3 A}$ and $u L 11^{K 3 Y}$, and 14 by the three genotypes, $u L 11^{K 3 A}, u L 11^{K 3 Y}$ and corto $^{L 1} /$ corto $^{420}$ (Figure 7A). qRT-PCR validations of RNA-seq data were performed for three genes: CG13516, one of the few genes to be deregulated in the three genotypes, $H s p 67 B c$, encoding a small heat-shock protein deregulated in corto ${ }^{L 1} / c{ }^{2}{ }^{420}$ and $u L 11^{K 3 Y}$, and GstE6, encoding a Glutathione S-transferase deregulated in $u L 11^{K 3 A}$ and $u L 11^{K 3 Y}$ (Figures 7B and C).

Strikingly, in corto ${ }^{L 1} /$ corto $^{420}$ mutants, $52.7 \%$ of the RPGs (89/169) were up-regulated (Supplementary Table 3). A similar enrichment of RPGs had been observed in flies 
overexpressing the Corto chromodomain (21). Our results thus indicated that this overexpression behaved as a dominant negative allele.

Contrarily to what we observed following overexpression of $u L 11$ (21), we did not find any deregulation of RPGs in imaginal discs of $u L 11$ mutants. Gene ontology analyses revealed that genes up-regulated in $u L 11^{K 3 A}$ imaginal discs are enriched in the category "glutathione metabolism" and down-regulated genes in the category "regulation of transcription" (Supplementary Table 3). The only enrichment found for $u L 11^{K 3 Y}$ was for upregulated genes in the category "glutathione metabolism" as for $u L 11^{K 3 A}$ (KEGG pathway, Benjamini adjusted p-value 5.90e-03).

In an attempt to identify the transcriptional partners of $\mathrm{UL} 11$, we searched for conserved motifs in the cis-regulatory sequences of the deregulated genes. As $u L 11^{\text {K3A }}$ displayed a global decrease in translational rate that might interfere with the transcriptional response, we focused on the 84 genes deregulated in $u L 11^{K 3 Y}$. Using MEME (32), we identified a 21 nucleotide-long consensus sequence present in the cis-regulatory sequences of 39 on the 84 genes (E-value: 2.1e-23). Using TomTom (31), we found that this motif significantly matched the 14 nucleotide-long binding site for Mad ( $p$-value: 4.9e-07), as well as the 11 nucleotide-long binding site for its partner Med ( $p$-value 1.11e-04 that together mediate the cellular response to the BMP pathway (Figure 7D and Supplementary Table 4).

\section{DISCUSSION}

We have previously shown that ribosomal protein uL11 interacts with the chromodomain of the Drosophila Enhancer of Trithorax and Polycomb Corto when trimethylated on lysine 3 (uL11K3me3) (21). uL11, Corto and RNA Polymerase II co-localize at many sites on polytene chromosomes and overexpression of $u L 11$ induces the transcription of many RPGs and RiBi genes. These data have confirmed that Drosophila uL11 is involved in transcription (35) and further suggest that the lysine 3 supports this extra-ribosomal activity. In the aim of testing this hypothesis, we generated mutant alleles of $u L 11$ using the CRISPR/Cas9 technology. By introducing a template to promote Homologous Directed Repair, we obtained a mutant in which the lysine was replaced by an alanine. However, we also obtained mutants harbouring indels probably obtained by Non-Homologous End Joining. Strikingly, the lysine 3 codon of uL11 was either deleted or substituted by another amino acid in all recovered mutants. Hence, it seems that a strong selection pressure occurs to maintain the $u L 11$ ORF, consistent with the haplo-insufficiency of this RPG.

\section{A single amino acid substitution generates a Minute phenotype}


The $u L 11^{K 3 A}$ allele produces very little homozygotes. Those are only males that hatch with a developmental delay larger than two days as compared to wild-type flies raised in the same conditions. Interestingly, $u L 11^{K 3 A}$ heterozygotes are also delayed but slightly less (about one day). In addition, $u L 11^{K 3 A}$ heterozygous females are frequently sterile making it necessary to carry out crosses of heterozygous $u L 11^{K 3 A}$ males with wild-type females and to genotype the offspring in order to maintain the stock. Hence, the $u L 11^{K 3 A}$ allele clearly appears dominant, which is also visible for other phenotypes, such as the shorter and thinner macrochaetes and the global decrease in translational rate. Reduced viability, notably of females, delayed development, thin bristles and dominance are signatures of the Minute mutations that have been more recently shown to correspond to RPG deletions (3). The associated phenotypes are thought to reflect a defect in ribosomal proteins' stoichiometry resulting in a decreased capacity for protein synthesis. In accordance, tissues that are the most dependent on translation are likely to be the most affected. For instance, high ribosome biogenesis level is suggested to be necessary for the maintenance of germinal stem cells in the Drosophila ovarium, which could explain the reduced fertility of Minute females $(36,37)$. Similarly, macrochaetes are described to require a very high amount of protein synthesis over a short developmental period (3). Unexpectedly, replacement of a single lysine by an alanine in the N-terminal tail of uL11 induces a Minute phenotype. Nevertheless, the global level of translation in the mutant is only slightly decreased and the mutated protein can be efficiently incorporated into translating ribosomes. However, translation speed or accuracy might be altered. Indeed, in yeast, $u L 11$ loss-of-function has been shown to halve translation speed and to cause increased amino acid mis-incorporation and termination codon readthrough (16). Another possibility would be that $\mathrm{uL} 11 \mathrm{~K} 3 \mathrm{~A}$ ribosomes display altered affinity for specific mRNA, as has been described for ribosomes lacking RPL38/eL38 in mice (38).

Surprisingly, the $u L 11^{K 3 Y}$ mutant does not display any Minute phenotype. The $\mathrm{N}$ terminal extension of uL11 is supposed to be unstructured as neither the first 6 nor the first 9 amino acids were resolved in the structure of the $D$. melanogaster and $S$. cerevisiae $80 S$ ribosome, respectively $(15,39)$. This region is composed of hydrophilic amino acids and could thus be a hub for protein interactions. Addition of methyl groups on lysines, even if it has no effect on the overall charge of the residue, increases its hydrophobicity. Trimethylation of uL11 lysine 3 might thus modulate the activity of the $\mathrm{N}$-terminal tail (40). However, in S. cerevisiae and pombe, deletion of the enzyme responsible for uL 11 lysine 3 methylation has little impact on ribosome assembly and function or on cell viability $(19,41)$ suggesting that the methylation of lysine 3 is not crucial for basic translational activity. In the $u L 11^{K 3 Y}$ mutant, the tyrosine, a hydrophobic residue, might mimic the effect of methyl groups. If this is the case, in-depth comparison of translation between $u L 11^{K 3 Y}$ and $u L 11^{K 3 A}$ mutants, including sequencing of 
polysomal mRNA, should permit to elucidate the role of the uL11 N-terminal tail methylation in translation.

\section{Extra-ribosomal activities of uL11}

Reduction in translation capacity might be indirect and due to extra-ribosomal activities of free ribosomal proteins $(20,41)$. Moreover, in nematodes and mammals, uL11 autoregulates its own expression by interfering with the splicing of its mRNA. Indeed, an excess of uL11 induces aberrant retention of an intron and elimination of the corresponding mRNA by Non-sense Mediated Decay $(8,7)$. We previously reported that overexpression of $u L 11$ increases the transcription of some RPGs and RiBi genes (21). The corresponding proteins might be produced, respecting the necessary stoichiometry for ribosome assembly, thus avoiding ribosomal stress. Our new data show that these genes are not down-regulated in the $u L 11$ lysine 3 mutants. Hence, the Minute phenotype of $u L 11^{K 3 A}$ does not result from transcriptional down-regulation of these genes, confirming that it should rather be due to an alteration in translation.

As the $u L 11^{K 3 Y}$ mutant displays neither Minute phenotypes nor a global decrease in translation, we assumed that solely its transcriptional activity would be affected. However, deep-sequencing of its transcriptome identified only 84 deregulated genes as compared to the reference line. Interestingly, the cis-regulatory sequences of a number of them share a nucleotide motif that significantly matches the binding site of the transcription factors Mad and Med, the effectors of the BMP pathway in Drosophila. Upon binding of the Decapentaplegic (Dpp) ligand to its heterodimeric serine/threonine kinase receptor, Mad is phosphorylated, translocates to the nucleus together with the Smad4 homolog Medea (Med) and regulates expression of target genes. This important pathway contributes notably to growth regulation and patterning [for a review see (44)]. Whether uL11 cooperates with Mad-Med in the regulation of transcription will remain to be demonstrated.

The absence of obvious phenotypes and the fact that only few genes are deregulated in $u L 11^{K 3 Y}$ mutant could mean that the extra-ribosomal function of $U L 11$ is not required under physiological conditions. Indeed, many extra-ribosomal functions are triggered under stress conditions. For example, in S. cerevisiae $u L 11 / R P L 12$ has been shown to regulate the PHO pathway in low phosphate conditions potentially at the transcriptional level. (9). It would thus be interesting to test whether the Drosophila $u L 11$ mutants, and especially $u L 11^{K 3 Y}$, display altered resistance to stresses that affect ribosome biogenesis, for instance by raising them with specific food diets.

\section{ACKNOWLEDGMENTS}


We thank the members of the team for stimulating discussions, Jean-Michel Gibert for critical reading of the manuscript, Immane R'Kiki for technical assistance, Naïra Naouar from the ARTbio Bioinformatics platform (IBPS) for the training of HG in NGS analyses, the Bloomington Stock Center for fly strains. This work was funded by the Centre National de la Recherche Scientifique (CNRS), Sorbonne University, and by a Fondation ARC grant to FP (PJA20171206407). HG was funded by a doctoral fellowship from the MESRI (Ministère de l'Enseignement Supérieur, de la Recherche et de l'Innovation) and a $4^{\text {th }}$ year doctoral fellowship from Fondation ARC (ARCDOC42020020001381). JD was funded by a doctoral fellowship from the MESRI and a $4^{\text {th }}$ year doctoral fellowship from the Fondation pour la Recherche médicale (FDT20160435164). This work was supported by the France Génomique national infrastructure, funded as part of the "Investissements d'Avenir" program managed by the Agence Nationale de la Recherche (contract ANR-10-INBS-0009).

\section{REFERENCES}

1. Schultz J. The Minute Reaction in the Development of Drosophila melanogaster. Genetics. 1929; 14(4):366-419.

2. Brehme KS. A Study of the Effect on Development of 'Minute' Mutations in Drosophila melanogaster. Genetics. 1939; 24(2):131-61.

3. Marygold SJ, Roote J, Reuter G, Lambertsson A, Ashburner M, Millburn GH, et al. The ribosomal protein genes and Minute loci of Drosophila melanogaster. Genome Biol. 2007; 8(10):R216.

4. Cook RK, Christensen SJ, Deal JA, Coburn RA, Deal ME, Gresens JM, et al. The generation of chromosomal deletions to provide extensive coverage and subdivision of the Drosophila melanogaster genome. Genome Biol. 2012; 13(3):R21.

5. Bhavsar RB, Makley LN, Tsonis PA. The other lives of ribosomal proteins. Hum Genomics. 2010; 4(5):327-44.

6. Ban N, Beckmann R, Cate JHD, Dinman JD, Dragon F, Ellis SR, et al. A new system for naming ribosomal proteins. Curr Opin Struct Biol. 2014; 24:165-9.

7. Cuccurese M, Russo G, Russo A, Pietropaolo C. Alternative splicing and nonsensemediated mRNA decay regulate mammalian ribosomal gene expression. Nucleic Acids Res. 2005; 33(18):5965-77.

8. Mitrovich $\mathrm{QM}$, Anderson $\mathrm{P}$. Unproductively spliced ribosomal protein $\mathrm{mRNAs}$ are natural targets of mRNA surveillance in C. elegans. Genes Dev. 2000; 14(17):2173-84.

9. Tu W-YY, Huang Y-CC, Liu L-FF, Chang L-HH, Tam MF. Rpl12p affects the transcription of the $\mathrm{PHO}$ pathway high-affinity inorganic phosphate transporters and repressible phosphatases. Yeast. 2011; 28(6):481-93.

10. Larkin A, Marygold SJ, Antonazzo G, Attrill H, dos Santos G, Garapati PV, et al. FlyBase: updates to the Drosophila melanogaster knowledge base. Nucleic Acids Res. 2021; 49(D1):D899-907. 
11. Lindsley DL, Sandler L, Baker BS, Carpenter AT, Denell RE, Hall JC, et al. Segmental aneuploidy and the genetic gross structure of the Drosophila genome. Genetics. 1972; 71(1):157-84.

12. Huang J, Wu S, Barrera J, Matthews K, Pan D. The Hippo signaling pathway coordinately regulates cell proliferation and apoptosis by inactivating Yorkie, the Drosophila Homolog of YAP. Cell. 2005; 122(3):421-34.

13. Park MH, Nishimura K, Zanelli CF, Valentini SR. Functional significance of elF5A and its hypusine modification in eukaryotes. Amino Acids. 2010; 38(2):491-500.

14. Gonzalo P, Reboud J-P. The puzzling lateral flexible stalk of the ribosome. Biol Cell. 2003; 95(3-4):179-93.

15. Anger AM, Armache J-P, Berninghausen O, Habeck M, Subklewe M, Wilson DN, et al. Structures of the human and Drosophila 80S ribosome. Nature. 2013; 497(7447):80-5.

16. Wawiórka L, Molestak E, Szajwaj M, Michalec-Wawiórka B, Boguszewska A, Borkiewicz $\mathrm{L}$, et al. Functional analysis of the uL11 protein impact on translational machinery. Cell Cycle. 2016; 15(8):1060-72.

17. Oliver KE, Rauscher R, Mijnders M, Wang W, Wolpert MJ, Maya J, et al. Slowing ribosome velocity restores folding and function of mutant CFTR. J Clin Invest. 2019; 28;129(12):5236-53.

18. Carroll AJ, Heazlewood JL, Ito J, Millar AH. Analysis of the Arabidopsis cytosolic ribosome proteome provides detailed insights into its components and their posttranslational modification. Mol Cell Proteomics. 2008; 7(2):347-69.

19. Sadaie M, Shinmyozu K, Nakayama J. A conserved SET domain methyltransferase, Set11, modifies ribosomal protein Rpl12 in fission yeast. J Biol Chem. 2008; 283(11):7185-95.

20. Webb KJ, Laganowsky A, Whitelegge JP, Clarke SG. Identification of Two SET Domain Proteins Required for Methylation of Lysine Residues in Yeast Ribosomal Protein Rpl42ab. J Biol Chem. 2008; 283(51):35561-8.

21. Coléno-Costes A, Jang SM, de Vanssay A, Rougeot J, Bouceba T, Randsholt NB, et al. New partners in regulation of gene expression: the Enhancer of Trithorax and Polycomb Corto interacts with methylated ribosomal protein L12 via its chromodomain. PLoS Genet. 2012; 8(10):e1003006.

22. Gratz SJ, Cummings AM, Nguyen JN, Hamm DC, Donohue LK, Harrison MM, et al. Genome engineering of Drosophila with the CRISPR RNA-guided Cas9 nuclease. Genetics. 2013; 194(4):1029-35.

23. Thomassin H, Kress C, Grange T. MethylQuant: a sensitive method for quantifying methylation of specific cytosines within the genome. Nucleic Acids Res. 2004; 32(21):e168.

24. Chevet $E$, Lemaître $G$, Katinka MD. Low concentrations of tetramethylammonium chloride increase yield and specificity of PCR. Nucleic Acids Res. 1995; 23(16):3343-4.

25. Bassett AR, Kong L, Liu J-LL. A genome-wide CRISPR library for high-throughput genetic screening in Drosophila cells. J Genet Genomics. 2015; 42(6):301-9. 
26. Wittwer CT, Reed GH, Gundry CN, Vandersteen JG, Pryor RJ. High-resolution genotyping by amplicon melting analysis using LCGreen. Clin Chem. 2003; 49(6 Pt 1):853-60.

27. Dardalhon-Cuménal D, Deraze J, Dupont CA, Ribeiro V, Coléno-Costes A, Pouch J, et al. Cyclin G and the Polycomb Repressive complexes PRC1 and PR-DUB cooperate for developmental stability. PLoS Genet. 2018; 14(7):e1007498.

28. Zamurrad S, Hatch HAM, Drelon C, Belalcazar HM, Secombe J. A Drosophila Model of Intellectual Disability Caused by Mutations in the Histone Demethylase KDM5. Cell Rep. 2018; 22(9):2359-69.

29. Miyoshi K, Okada TN, Siomi H, Siomi MC. Biochemical Analyzes of Endogenous Argonaute Complexes Immunopurified with Anti-Argonaute Monoclonal Antibodies. In: Hobman TC, Duchaine TF, editors. Methods in Molecular Biology; vol. 725. Argonaute Proteins. Totowa, NJ: Humana Press; 2011; p. 29-43.

30. Mouchel-Vielh E, Rougeot J, Decoville M, Peronnet F. The MAP kinase ERK and its scaffold protein MP1 interact with the chromatin regulator Corto during Drosophila wing tissue development. BMC Dev Biol. 2011; 11:17.

31. Gupta S, Stamatoyannopoulos JA, Bailey TL, Noble W. Quantifying similarity between motifs. Genome Biol. 2007; 8(2):R24.

32. Bailey, T. L., Elkan,C. Fitting a mixture model by expectation maximization to discover motifs in biopolymers. Proceedings of the second international conference on intelligent systems for molecular biology. 1994; 28-36.

33. Bailey TL, Boden M, Buske FA, Frith M, Grant CE, Clementi L, et al. MEME SUITE: tools for motif discovery and searching. Nucleic Acids Res. 2009; 1;37:W202-8.

34. Pfaffl MW. A new mathematical model for relative quantification in real-time RT-PCR. Nucleic Acids Res. 2001; 29(9):e45.

35. Brogna S, Sato T-AA, Rosbash M. Ribosome components are associated with sites of transcription. Mol Cell. 2002; 10(4):93-104.

36. Zhang Q, Shalaby NA, Buszczak M. Changes in rRNA Transcription Influence Proliferation and Cell Fate Within a Stem Cell Lineage. Science. 2014; 17;343(6168):298-301.

37. Sanchez CG, Teixeira FK, Czech B, Preall JB, Zamparini AL, Seifert JRK, et al. Regulation of Ribosome Biogenesis and Protein Synthesis Controls Germline Stem Cell Differentiation. Cell Stem Cell. 2016; 18(2):276-90.

38. Xue S, Tian S, Fujii K, Kladwang W, Das R, Barna M. RNA regulons in Hox 5' UTRs confer ribosome specificity to gene regulation. Nature. 2015; 517(7532):33-8.

39. Ben-Shem A, de Loubresse NG, Melnikov S, Jenner L, Yusupova G, Yusupov M. The Structure of the Eukaryotic Ribosome at 3.0 A Resolution. Science. 2011; 334:7.

40. Beaver JE, Waters ML. Molecular Recognition of Lys and Arg Methylation. ACS Chem Biol. 2016; 18;11(3):643-53. 
41. Porras-Yakushi TR, Whitelegge JP, Clarke S. A novel SET domain methyltransferase in yeast: Rkm2-dependent trimethylation of ribosomal protein L12ab at lysine 10. J Biol Chem. 2006; 281(47):35835-45.

42. Wool IG. Extraribosomal functions of ribosomal proteins. Trends Biochem Sci. 1996; 21(5):164-5.

43. Warner JR, McIntosh KB. How common are extraribosomal functions of ribosomal proteins? Mol Cell. 2009; 34(1):3-11.

44. Matsuda S, Harmansa S, Affolter M. BMP morphogen gradients in flies. Cytokine Growth Factor Rev. 2016; 27:119-127. 


\section{Figure 1: Genomic organization of the uL11 locus}

A - Genomic locus of the $2 R$ chromosome containing the $u L 11 / R p L 12$ gene (coordinates in grey).

B - Sequence of the $u L 11^{K 3 A}$ and $u L 11^{K 3 Y}$ mutants.

A

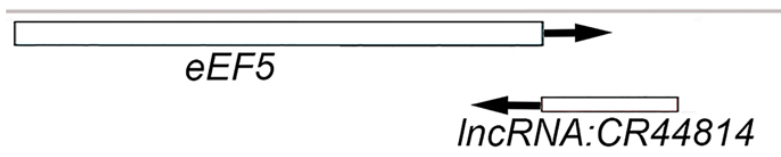

uL11/RPL12

IncRNA:CR44814
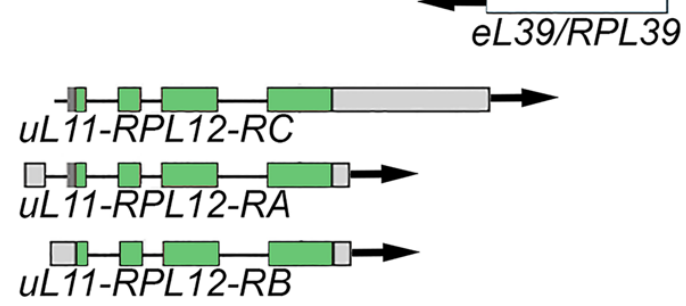

B

+ ACCGCTATGCCTCCCAAATTCGACCCAACGGAA

КЗА ACCGCTATGCCTCCCGCCTTCGACCCAACGGAA

KЗY ACCGCTATGCCTCCCTACTTCGACCCAACGGAA 
Figure 2: uL11K3me3 is undetectable in homozygous uL11 mutants

Tubulin was used as a loading control. Whereas UL11 was present in hetero- and homozygous mutants, as revealed by the pan-uL11 antibody, uL11K3me3 was undetectable in the two homozygous mutants.

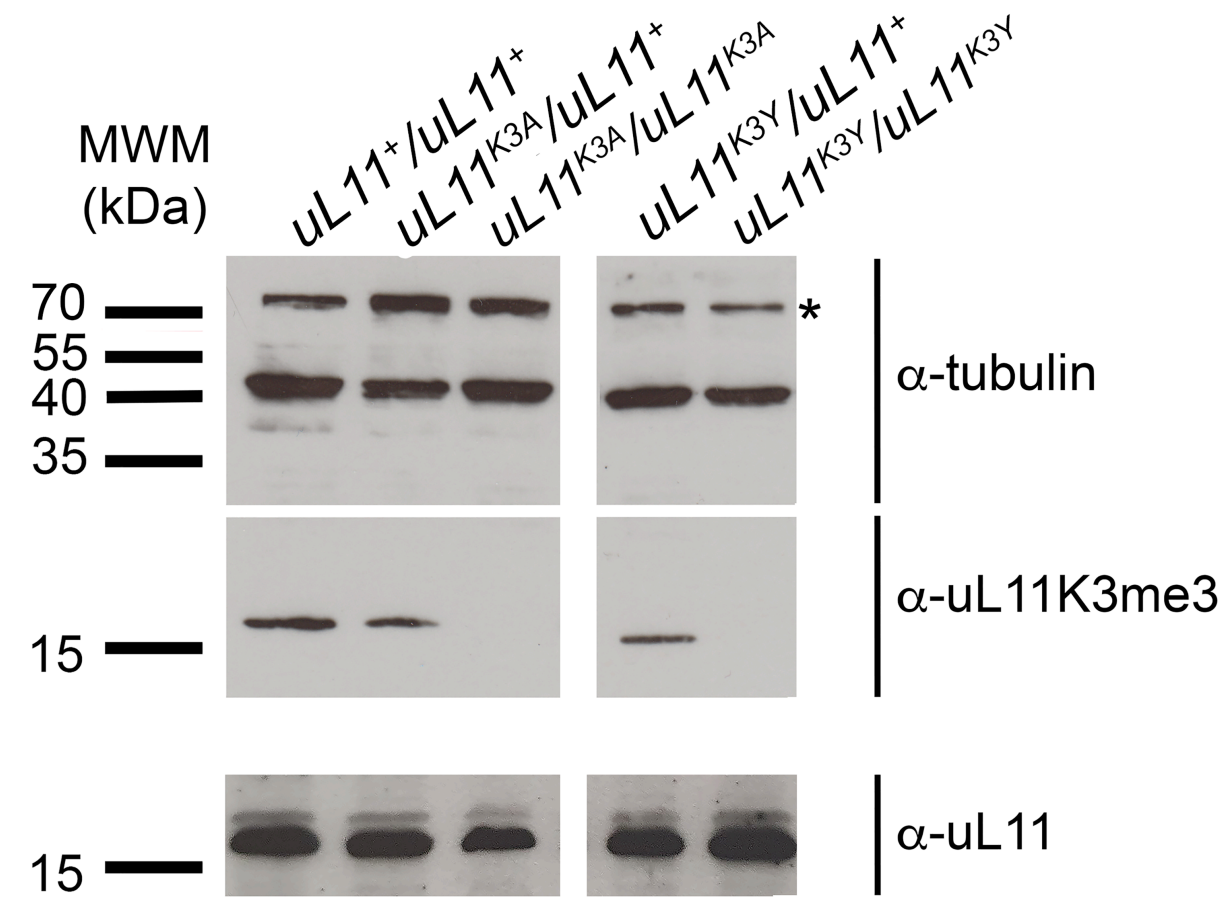




\section{Figure 3: Life history traits of uL11 mutants}

A - Lethality of $u L 11$ mutants. $u L 11^{X} / C y O, D f d-E Y F P$ flies were crossed between them and 300 embryos per genotype were transferred on new medium $\left(u L 11^{X}: u L 11^{+}, u L 11^{K 3 A}\right.$ or $u L 11^{K 3 Y}$, as indicated). Left: percentage of $u L 11^{X} / u L 11^{X}$ and $u L 11^{X} / C y O, D f d-E Y F P$ first instar larvae emerged from 300 embryos; Right: percentage of $u L 11^{x} / u L 11^{x}$ and $u L 11^{X} / C y O, D f d$ EYFP pupae coming from the emerged first instar larvae. Numbers of starting embryos and larvae are indicated.

$u L 11^{X} / u L 11^{X}$ individuals: dark colour; $u L 11^{X} / C y O, D f d-E Y F P$ individuals: light colour; blue: $u L 11^{+}$, burgundy: $u L 11^{K 3 A}$, orange: $u L 11^{K 3 Y}$; grey: $u L 11^{X} / u L 11^{X}$ or $u L 11^{X} / C y O, D f d-E Y F P$.

B - Developmental time of $u L 11$ mutants. The percentage of flies emerged from day 8 to 15 is shown. The total number of emerged flies is indicated. Solid lines: heterozygous flies; dotted line: homozygous flies; blue: $u L 11^{+}$, burgundy: $u L 11^{K 3 A}$, orange: $u L 11^{K 3 Y}$.

$\mathrm{Chi}^{2}$ test: ${ }^{* * *} p$-value $<0.001 ;{ }^{* *} p$-value $<0.01 ;{ }^{*} p$-value $<0.05$; only significant comparisons are shown.

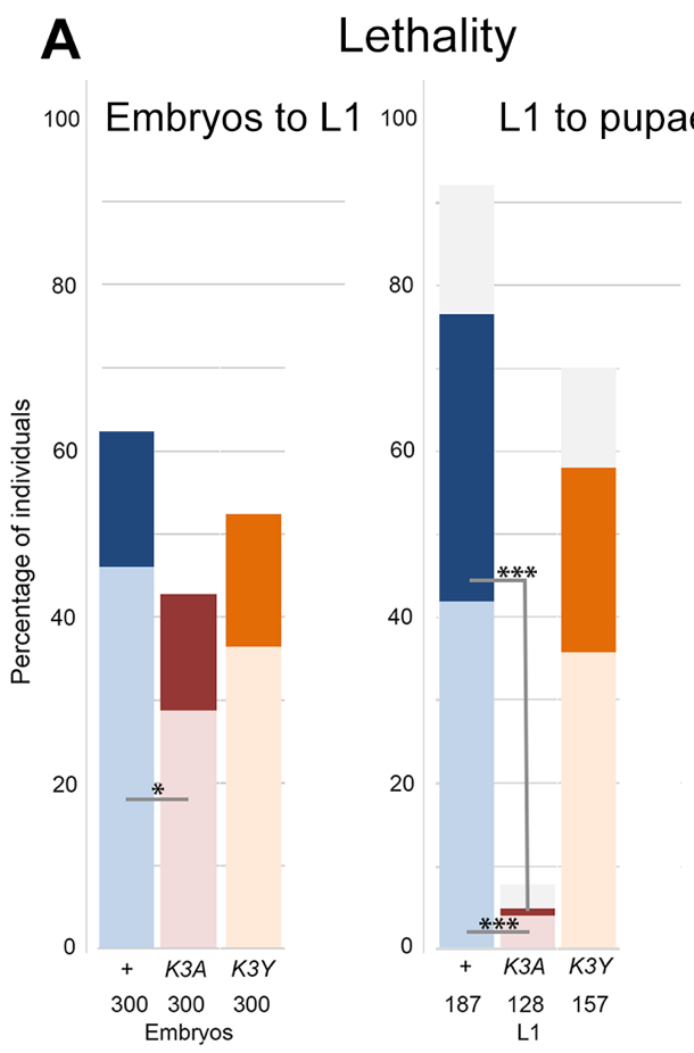

B

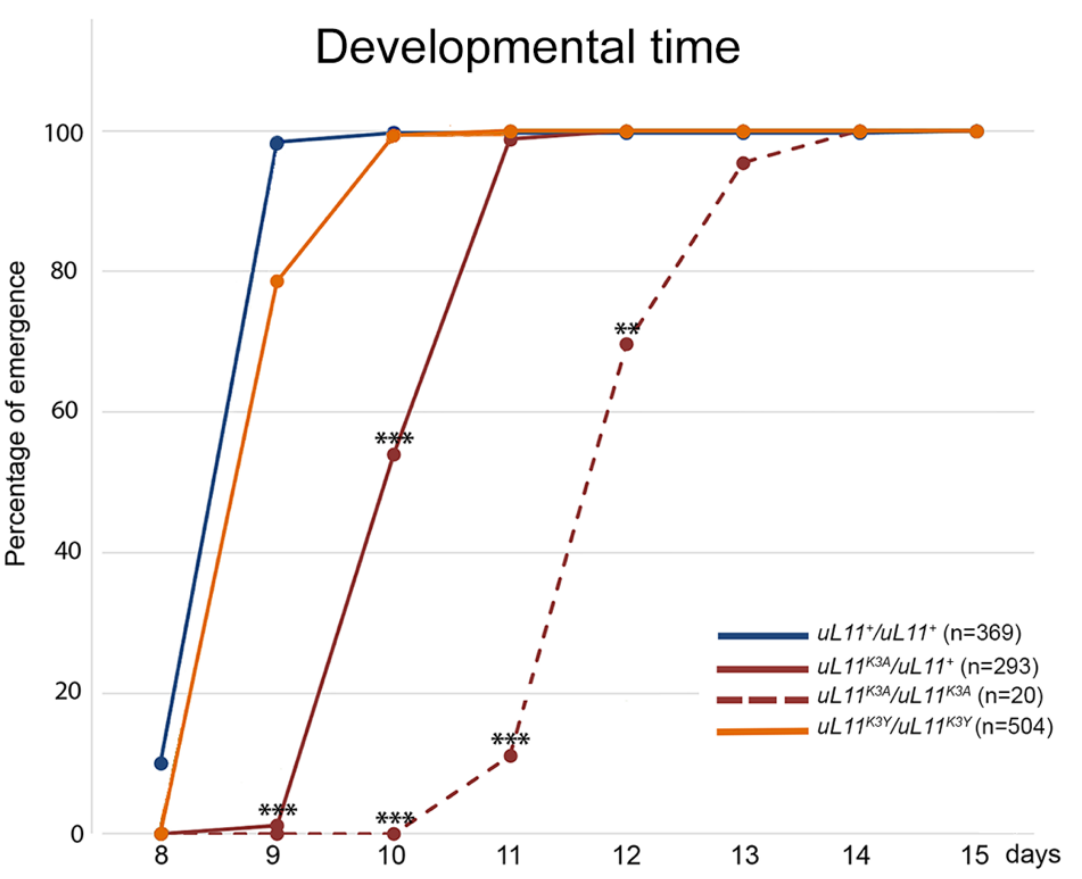




\section{Figure 4: Analysis of bristles and wings in male uL11 mutants}

A - Thorax of a wild-type male. Anterior and posterior scutellar bristles are colorized.

B - Thorax of a $u L 11^{K 3 A} / U L 11^{K 3 A}$ male. Anterior and posterior scutellar bristles are colorized.

Note that they look thinner and shorter that those of the wild-type male shown in A.

C - Length of anterior scutellar bristles of wild-type males (blue; $n=45$ ), $u L 11^{K 3 A} / u L 11^{+}$and $u L 11^{K 3 A} / U L 11^{K 3 A}$ (dark and light burgundy, $\mathrm{n}=55$ and $\mathrm{n}=24$, respectively) and $u L 11^{K 3 Y} / U L 11^{K 3 Y}$ (orange, $\mathrm{n}=51$ ).

D - Length of posterior scutellar bristles of wild-type males (blue; $n=44$ ), $u L 11^{K 3 A} / u L 11^{+}$and $u L 11^{K 3 A} / U L 11^{K 3 A}$ (dark and light burgundy, $\mathrm{n}=53$ and $\mathrm{n}=13$, respectively) and $u L 11^{K 3 Y} / u L 11^{K 3 Y}$ (orange, $\mathrm{n}=50$ ).

E - Wing length of $u L 11$ wild-type males (blue; $n=28$ ), $u L 11^{K 3 A} / u L 11^{+}$and $u L 11^{K 3 A} / u L 11^{K 3 A}$ (dark and light burgundy, $n=30$ and $n=15$, respectively) and $u L 11^{K 3 Y} / u L 11^{K 3 Y}$ (orange, $n=30)$.

t-tests: ${ }^{* * *}$ p-value $<0.001$; ns: non significant.

A

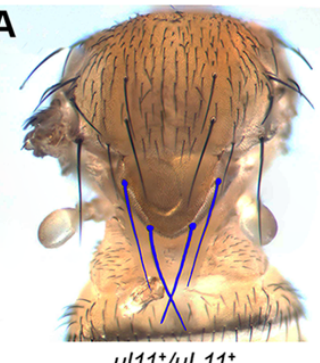

C

Length of anterior scutellar bristles

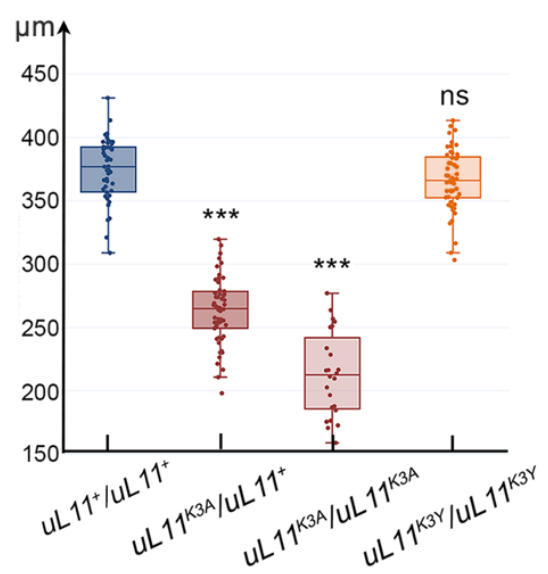

B

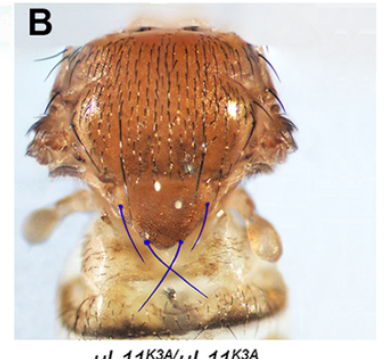

D

Length of posterior scutellar bristles

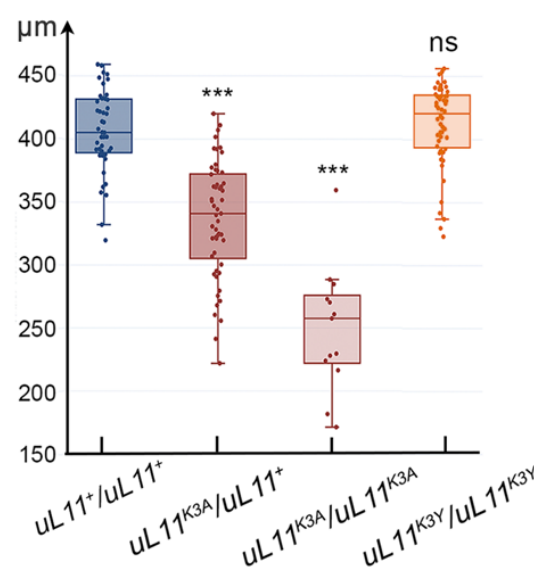

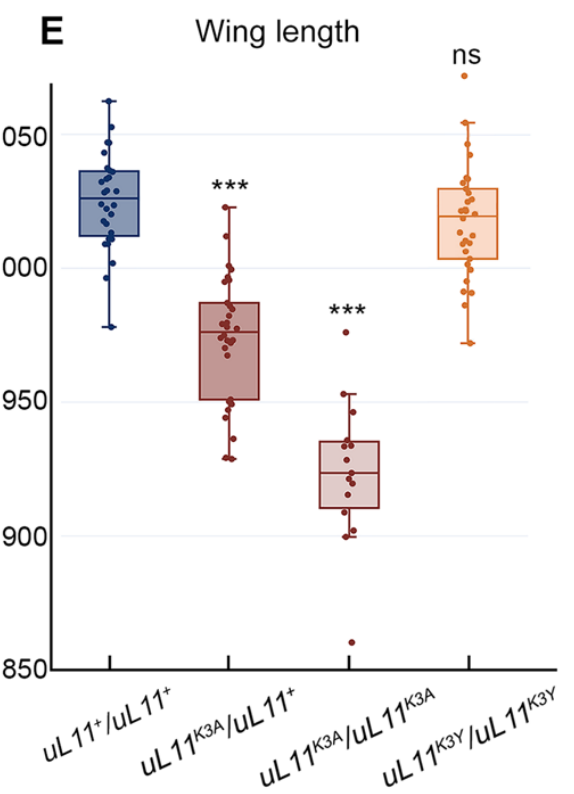




\section{Figure 5: Translational rate of $u L 11$ mutants}

A - Western blot showing puromycin incorporation in larvae of the two mutants as compared to wild-type larvae, in absence (-) or presence $(+)$ of cycloheximide $(\mathrm{CHX})$, an inhibitor of translation. Puromycin incorporation was revealed with an anti-puromycin antibody. Histone $\mathrm{H} 3$, revealed with an anti-panH3 antibody, was used as loading control. MWM: molecular weight marker.

B - Quantification of the puromycin signal in the 4 genotypes without (-) or with (+) $\mathrm{CHX}$ treatment. The puromycin signal was first normalized to the $\mathrm{H} 3$ signal, then to the wild-type signal. Student's t-tests were performed to compare puromycin incorporation in mutant and wild-type larvae. ${ }^{*}$ p-value $<0.05$; ns: non significant.

C - Polysome fractionation: cytoplasmic lysates (left) and EDTA-treated lysates (right) from S2 cells expressing uL11WT-HA (top) or uL11K3A-HA (bottom) were fractionated by centrifugation onto a sucrose gradient. Optical density at $254 \mathrm{~nm}$ was monitored during fractionation (top panels). The peaks observed in the gradient correspond to the different ribosomal complexes: 40S subunit, 605 subunit, $80 \mathrm{~S}$ monosome, polysomes. Proteins extracted from fractions were analyzed by Western blotting with anti-HA antibody (lower panels). A vertical line indicates that different wells from the same gel were juxtaposed in the image for clarity. Images are representative for three obtained replicates.

A
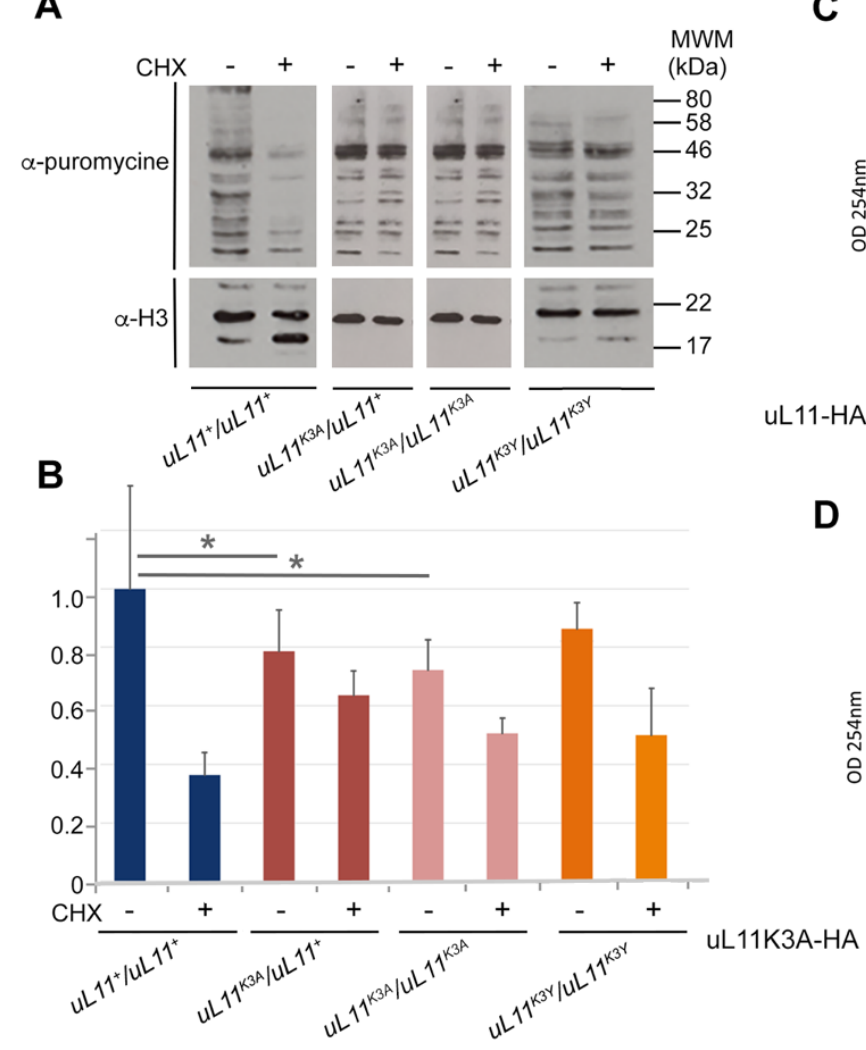

C

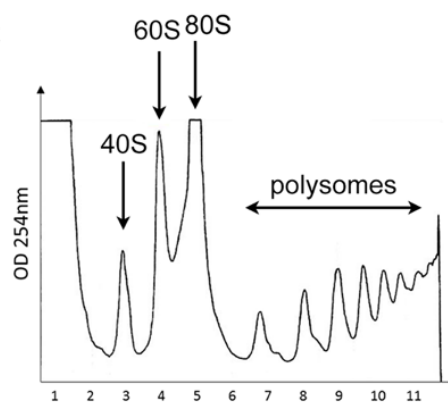

uL11-HA

D

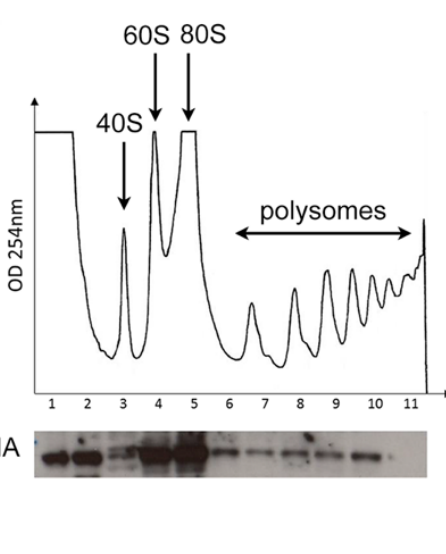

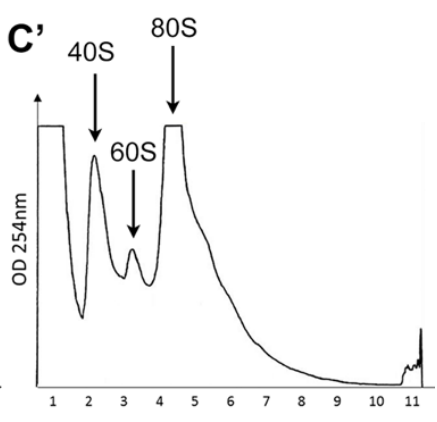

D'

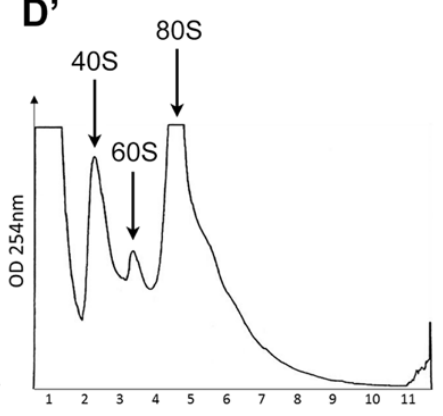

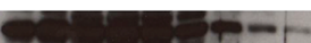


Figure 6: uL11 but neither uL11K3A nor uL11K3Y co-immunoprecipitates with the chromodomain of Corto.

S2 cells were co-transfected with plasmids expressing FLAG-CortoCD and uL11-Myc, uL11K3A-Myc or uL11K3A-Myc. Immunoprecipitations were performed with anti-FLAG antibodies ( $\alpha$-FLAG) or anti-HA antibodies (mock) and Western blot revealed using $\alpha$-FLAG or anti-Myc antibodies ( $\alpha-M y c)$. Spnt: supernatant, IP: immunoprecipitation. A - FLAGCortoCD co-immunoprecipitated with uL11-Myc (arrow). B - FLAG-CortoCD did not coimmunoprecipitate with UL11K3A-Myc. C - FLAG-CortoDCD did not co-immunoprecipitate with uL11K3Y-Myc.

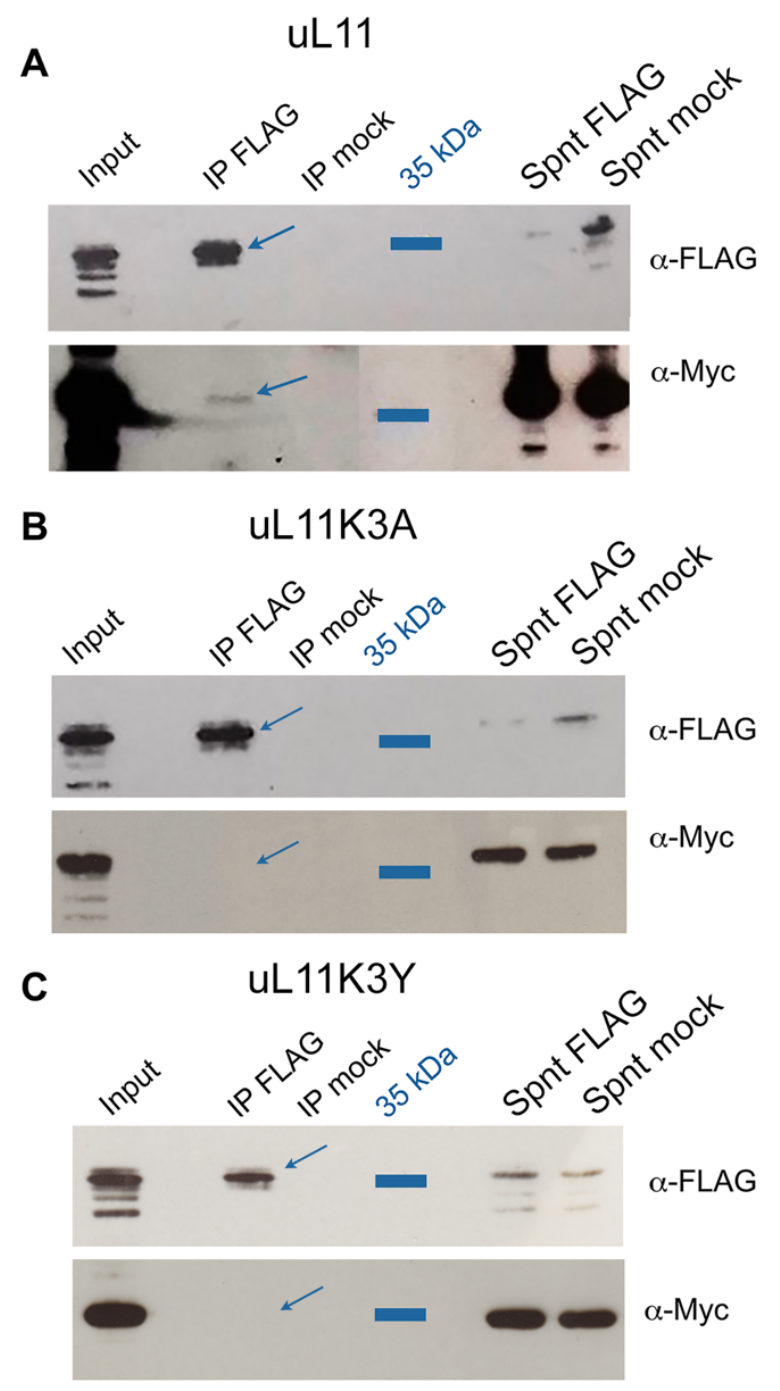




\section{Figure 7: RNA-seq analyses of corto and uL11 mutants.}

A - Venn diagrams showing the intersection of genes deregulated in $\operatorname{corto}^{L 1} /$ corto $^{420}, u L 11^{K 3 A}$ and $u L 11^{K 3 Y}$ up- and down-regulated genes together (cutoffs: adjusted p-value < 0.05 ; $\log _{2}$ (fold-change) $<-0.5$ ou $>0.5$ ). See Supplementary Table 2 for detailed gene lists. The three genes validated by qRT-PCR are indicated.

B - RT-qPCR analysis of CG13516, Hsp67Bc and GstE6 expression in corto ${ }^{L 1} /$ corto $^{420}$, $U L 11^{K 3 A}$ and $U L 11^{K 3 Y}$ wing imaginal discs. Expressions were normalized on the geometric mean of GAPDH and Spt6. Mean of three replicates. Error bars correspond to standard deviations. ${ }^{*} p$-value $<0.05 ;{ }^{* *} p$-value $<0.01$; ${ }^{* * *} p$-value $<0.001$.

C - 21 nucleotide-long motif (top) found in the cis-regulatory sequences of 39 genes deregulated in the $u L 11^{K 3 Y}$ mutant (see Supplementary Table 4 for details). This motif significantly overlaps the transcription factors Mad (idmmpmm2009 database, p-value 4.9e07) and Med (dmmpmm2009 database, p-value 1.22e-04) motifs.

D - Snapshots showing the mapping of reads on CG13516, Hsp67Bc and GstE6 in the reference line $w^{1118}$, corto ${ }^{420} /$ corto $^{L 1}, u L 11^{K 3 A}$ and $u L 11^{K 3 Y}$ wing imaginal discs. 

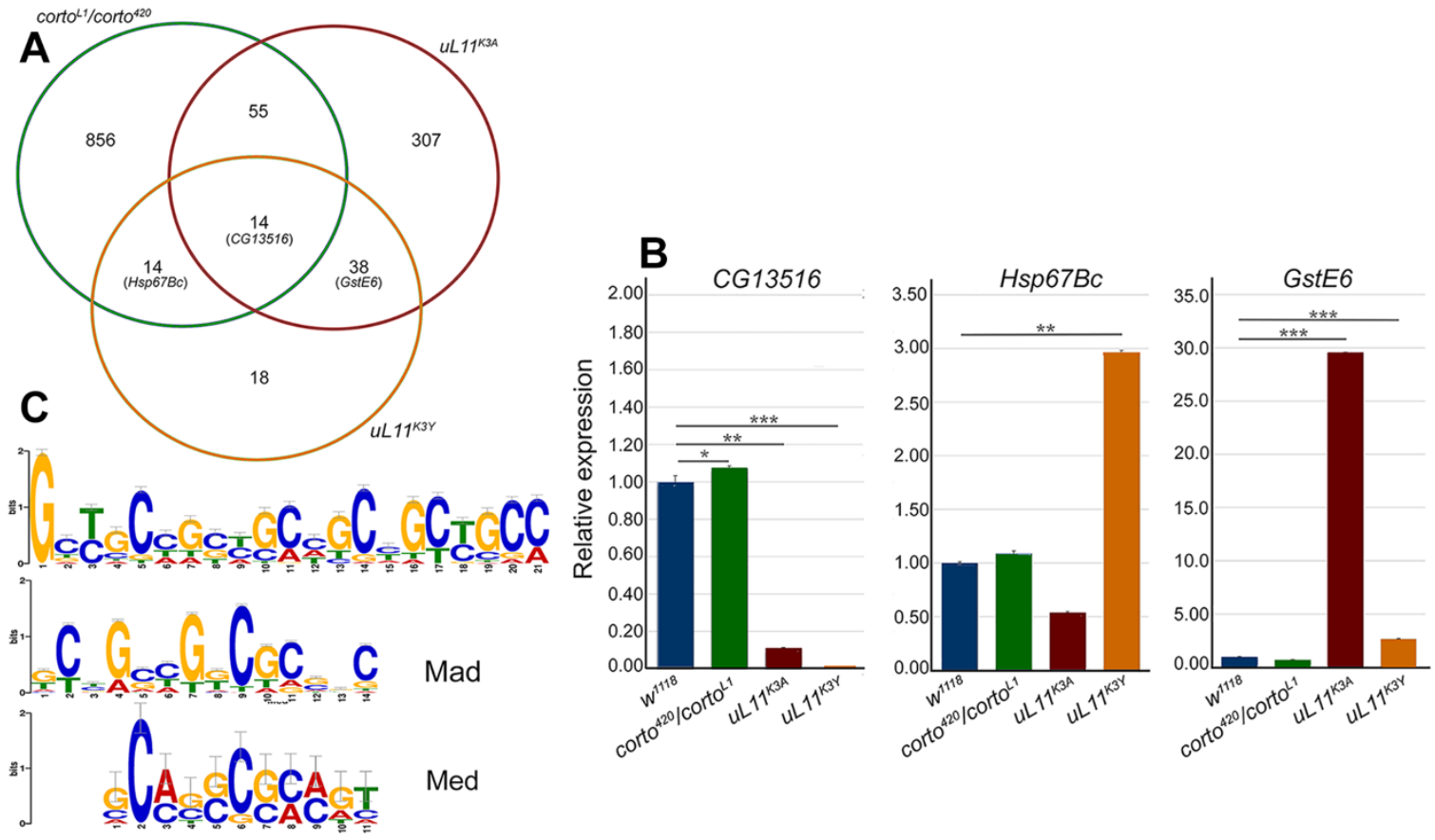

D

CG13516

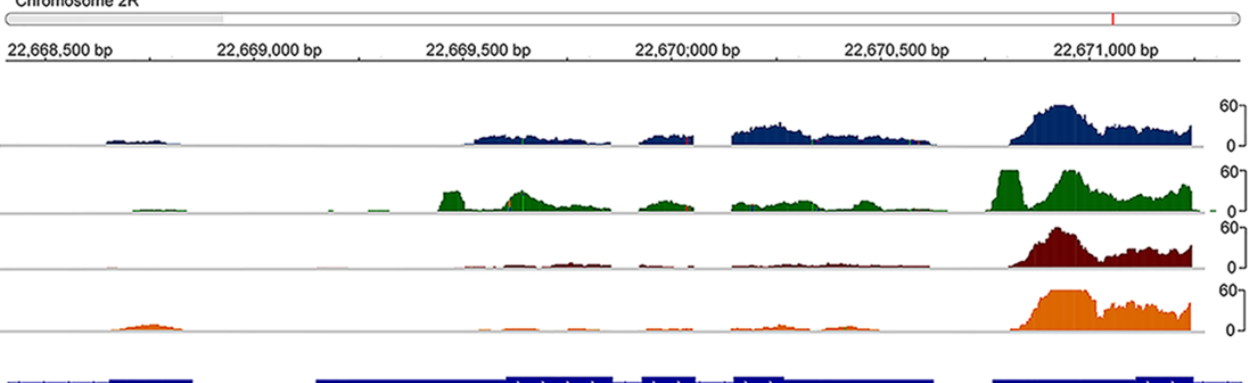

Refseq Genes

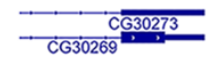

Hsp67Bc

Chromosome 3L

$9.372 .000 \mathrm{bp}$
$9,372.400 \mathrm{bp}$ $9,372,800 \mathrm{bp}$

$$
\begin{array}{r}
w^{1118} \\
\text { corto }^{420} / \text { corto }^{L 1} \\
u L 11^{K 3 A} \\
u L 11^{K 3 Y}
\end{array}
$$

Refseq Genes

\begin{tabular}{ccc}
\multicolumn{2}{c}{ GStE6 } \\
$\qquad \begin{array}{c}\text { Chromosome 2R } \\
18,405,800 \mathrm{bp}\end{array} 18,406,200 \mathrm{bp}$ & $18,406,600 \mathrm{bp}$ & $18,407,000 \mathrm{bp}$ \\
\hline
\end{tabular}

$$
\begin{gathered}
w^{1118} \\
\text { corto }^{420} / \text { corto }^{L 1} \\
u L 11^{K 3 A} \\
u L 11^{K 3 Y}
\end{gathered}
$$$$
u L 11^{K 3 A}
$$$$
u L 11^{\text {K3Y }}
$$ \\ $u L 11^{K 3 A}$
$u L 11^{K 3 Y}$}

Refseq Genes
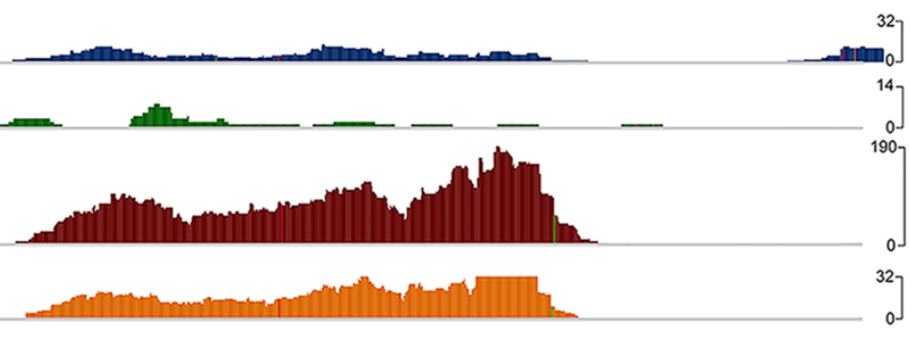
bioRxiv preprint doi: https://doi.org/10.1101/2021.08.18.456895; this version posted August 19, 2021. The copyright holder for this preprint (which was not certified by peer review) is the author/funder. All rights reserved. No reuse allowed without permission.

Table 1: RNA-seq of wing imaginal discs (GEO accession number GSE181926).

\begin{tabular}{|c|c|c|c|c|c|c|}
\hline Sample name & Genotype & Total reads & Aligned reads & Unmap reads & $\begin{array}{l}\text { Reads with multiple } \\
\text { alignment }\end{array}$ & $\begin{array}{l}\text { Reads used for } \\
\text { analysis }\end{array}$ \\
\hline wc_1 & $w^{1118} ;$ corto $^{+}$ & $1.50 \mathrm{E}+07$ & $6.70 \mathrm{E}+06$ & $9.00 \mathrm{E}+05$ & $2.20 \mathrm{E}+06$ & $6.71 \mathrm{E}+06$ \\
\hline wc_2 & $w^{1118} ;$ corto $^{+}$ & $1.50 \mathrm{E}+07$ & $6.40 \mathrm{E}+06$ & $1.20 \mathrm{E}+06$ & $2.20 \mathrm{E}+06$ & $6.44 \mathrm{E}+06$ \\
\hline cortoL1420_1 & $w^{1118} ;$ corto $^{L 1}$ /corto $^{420}$ & $2.71 \mathrm{E}+07$ & $1.18 \mathrm{E}+07$ & $1.20 \mathrm{E}+06$ & $1.20 \mathrm{E}+07$ & $1.18 \mathrm{E}+07$ \\
\hline cortoL1420_2 & $w^{1118} ;$ corto $^{L 1} /$ corto $^{420}$ & $2.71 \mathrm{E}+07$ & $1.14 \mathrm{E}+07$ & $1.90 \mathrm{E}+06$ & $1.20 \mathrm{E}+07$ & $1.14 \mathrm{E}+07$ \\
\hline$w_{-} 1$ & $w^{1118} ; u L 11^{+}$ & $2.58 \mathrm{E}+07$ & $3.88 \mathrm{E}+07$ & $5.39 \mathrm{E}+05$ & $1.71 \mathrm{E}+07$ & $2.08 \mathrm{E}+07$ \\
\hline w_2 & $w^{1118} ; u L 11^{+}$ & $3.22 \mathrm{E}+07$ & $4.03 E+07$ & $3.50 \mathrm{E}+05$ & $1.17 \mathrm{E}+07$ & $2.79 \mathrm{E}+07$ \\
\hline w_3 & $w^{1118} ; u L 11^{+}$ & $3.49 \mathrm{E}+07$ & $4.87 \mathrm{E}+07$ & $6.90 \mathrm{E}+05$ & $1.87 \mathrm{E}+07$ & $2.86 \mathrm{E}+07$ \\
\hline K3A_1 & $w^{1118} ; u L 11^{K 3 A}$ & $2.53 \mathrm{E}+07$ & $3.34 \mathrm{E}+07$ & $1.62 \mathrm{E}+06$ & $1.14 \mathrm{E}+07$ & $2.00 \mathrm{E}+07$ \\
\hline K3A_2 & $w^{1118} ; u L 11^{K 3 A}$ & $4.01 \mathrm{E}+07$ & $1.54 \mathrm{E}+07$ & $4.96 \mathrm{E}+06$ & $1.38 \mathrm{E}+08$ & $1.06 \mathrm{E}+07$ \\
\hline K3A_3 & $w^{1118} ; u L 11^{K 3 A}$ & $3.28 \mathrm{E}+07$ & $8.30 \mathrm{E}+07$ & $2.93 E+06$ & $6.18 \mathrm{E}+07$ & $1.97 \mathrm{E}+07$ \\
\hline K3Y_1 & $w^{1118} ; u L 11^{K 3 Y}$ & $3.07 \mathrm{E}+07$ & $3.87 E+07$ & $4.65 E+05$ & $1.14 \mathrm{E}+07$ & $2.64 \mathrm{E}+07$ \\
\hline
\end{tabular}

